\title{
Strong feeding preference of an exotic generalist herbivore for an exotic forb: a case of invasional antagonism
}

\author{
Kimberly J. La Pierre • W. Stanley Harpole • \\ Katharine N. Suding
}

Received: 30 October 2008/ Accepted: 9 January 2010/Published online: 20 January 2010

(C) The Author(s) 2010. This article is published with open access at Springerlink.com

\begin{abstract}
Many hypotheses dealing with the success of invasive plant species concern plant-herbivore interactions. The invasional meltdown and enemy inversion hypotheses suggest that non-native herbivores may indirectly facilitate the invasion of a non-native plant species by either favorably changing environmental conditions or reducing competition from native plant species. Our objective was to determine the role of herbivory by the non-native snail Otala lactea in structuring California grassland communities. We conducted two experiments to
\end{abstract}

Kimberly J. La Pierre-formerly Kimberly J. Komatsu.

K. J. La Pierre · W. S. Harpole - K. N. Suding

Department of Ecology and Evolutionary Biology,

University of California at Irvine, Irvine, CA 92697-2525,

USA

K. J. La Pierre ( $₫)$

Department of Ecology and Evolutionary Biology,

Yale University, New Haven, CT 06511, USA

e-mail: kimberly.komatsu@yale.edu

Present Address:

W. S. Harpole

Department of Ecology, Evolution, and Organismal

Biology, Iowa State University, Ames, IA 50011, USA

Present Address:

K. N. Suding

Department of Environmental Science, Policy,

and Management, University of California at Berkeley,

Berkeley, CA 94720, USA examine the feeding preferences of $O$. lactea for eight representative grassland species. Overall, O. lactea preferred Brassica nigra, a non-native forb, over all other species tested. Field monocultures of B. nigra supported significantly higher snail densities than monocultures of any of the other species tested. O. lactea also preferred B. nigra over all other species tested in controlled laboratory feeding trials. However, based on trait comparisons of each of the eight grassland species, we cannot pinpoint the preference for $B$. nigra to a basic nutritional requirement on the part of the herbivore or an allocation to defense on the part of the plants. Our study provides evidence for an antagonistic relationship between a non-native herbivore and a non-native plant species in their invasive range. We term this relationship “invasional antagonism".

Keywords Grassland - Invasional antagonism · Herbivory $\cdot$ Otala lactea $\cdot$ Brassica nigra

\section{Introduction}

The potential for non-native species to influence community structure has become widely accepted over the past few decades (Crooks 2002; Hoffmeister et al. 2005; Levine et al. 2003). Past examples of successful invaders are often those which affect trophic interactions in a system (Shea and Chesson 2002). Indeed, many hypotheses concerning invasion 
success focus on enemies (Catford et al. 2009). These hypotheses can be broken down into those in which the enemies impede the success of the invasive species (ex. biotic resistance) and those in which the enemies (or lack thereof) facilitate invasion (ex. enemy release/reduction, invasional meltdown, enemy inversion). While these hypotheses encompass a broad range of possible plant-herbivore interactions, they largely ignore what could be a very common phenomenon in invasion ecology: that an herbivore would prefer a plant from its native range and therefore inhibit its invasion success in the exotic range.

The current hypotheses surrounding the impact of enemies on plant invasion predict very different dynamics. The "biotic resistance hypothesis" suggests that native herbivores and competitors can reduce the ability of non-native plant species to invade a new territory (Levine et al. 2004). Conversely, invasive plants may be more successful in their invaded range as a result of the loss of their natural enemies that limit the plants in their native ranges, termed the "enemy release hypothesis" (Keane and Crawley 2002). An invasive plant's natural enemies can also follow it from its native range into its exotic range. Exotic herbivores that are intentionally released as biocontrol for an invasive plant species are expected to have a negative effect on the target plant, while having little to no effect of the native community. Thus, these biocontrol agents are not expected to become invasive themselves.

An invasive plant's natural enemies can also be accidentally introduced to its invasive range. It has been suggested that herbivores which co-occur with a plant species in its native range may act to promote the invasion of that plant species in a novel environment, generally by altering the environment to make it more favorable for the plant (Simberloff and Von Holle 1999). This process has been termed "invasional meltdown" (Simberloff and Von Holle 1999). Similarly, the "enemy inversion hypothesis" suggests that the invader's natural enemies may be either less effective in its invaded range or have a stronger effect on the native community than on the invader (Colautti et al. 2004). Several examples of failed biocontrol agents emphasize this point (Cowie 2001; Pearson et al. 2000; Sabath et al. 1981).

Otala lactea, commonly known as the Spanish Milk Snail, is a non-native snail species that originated in North Africa and southwestern Europe, but is now widespread in southern California grasslands (Elliott and Pierce 1992). O. lactea is considered a generalist herbivore in its native range, but its preferred hosts and impact on plant communities in this invasive range are unknown. Our goal was to determine the effect of $O$. lactea on invasive plants in southern California grasslands. Based on prevailing theory (i.e., enemy inversion and invasional meltdown) suggesting that accidentally introduced herbivores should have a positive effect on plant invaders which they co-occur with in their native range, we hypothesized that $O$. lactea would prefer to eat plant species which are native to the southern California grasslands while avoiding the non-native plant species, particularly those which co-occur with $O$. lactea in its native range. This selective herbivory would result in a negative effect of $O$. lactea on the growth of native species, thus facilitating the invasion of southern California grasslands by the non-native plant species.

We examined the feeding behavior of $O$. lactea when presented with native and non-native species common to southern California grasslands, in both planted monocultures in the field and in controlled feeding trials in the laboratory. Additionally, we determined the relative growth rates and carbon to nitrogen $(\mathrm{C}: \mathrm{N})$ ratios of the leaf tissue from each of our grassland species as indexes of general food quality, in order to identify a potential underlying cause for the preference of $O$. lactea for one grassland species over the others.

\section{Methods}

Experiment I: field snail density measurements

To determine feeding behavior of $O$. lactea in a field setting, we established monocultures of eight grassland species, four native and four non-native, in a typical degraded grassland located on the Irvine Ranch Land Reserve in Orange County, California in the winter of 2004. Native species were Bromus carinatus (perennial grass), Eschscholzia californica (annual or biennial forb), Nassella pulchra (perennial grass), and Vulpia michrostachys (annual grass). Non-native species were Bromus diandrus (annual grass), Bromus hordeaceus (annual grass), Brassica 
nigra (annual forb), and Cynara cardunculus (perennial forb).

In November of 2004 the experimental area was mowed and the systemic herbicide Roundup (Monsanto Corporation) was applied. Five replicate blocks of eight $1 \mathrm{~m} \times 1.5 \mathrm{~m}$ plots separated by $1 \mathrm{~m}$ aisles were established. In December of 2004 the residual litter was raked from each plot and the seeds of our eight experimental species were sowed, with one species per plot and a total seed density of $10 \mathrm{~g} / \mathrm{m}^{2}$. Plots were weeded three times during the growing season and a forb-specific (Ortho Weed-B-Gon) or grass-specific (Ortho Grass-B-Gon) herbicide was used midseason (March 17, 2005) as appropriate to the composition of each plot in order to minimize manual weed removal. There were no significant differences among plots in the weed biomass removed (see Harpole and Suding 2007). O. lactea individuals were allowed to naturally colonize all plots and on May 9, 2005, the number of O. lactea individuals in each monoculture was counted. Because the count data violated the parametric assumptions of normality, we compared snail densities in the monocultures in a Kruskal-Wallis test using Systat version 11 (Systat Inc, Chicago, Illinois).

\section{Experiment II: laboratory feeding} preference trials

To confirm that the field patterns observed in our first experiment indicated the feeding behavior of O. lactea, seedlings of the same eight grassland species (B. carinatus, E. californica, N. pulchra, V. michrostachys, B. diandrus, B. hordeaceus, B. nigra, and C. cardunculus) were subjected to herbivory by $O$. lactea under controlled conditions in the greenhouse. For each species, a single seedling was grown in sand in a conical pot, $5 \mathrm{~cm}$ in diameter and $20 \mathrm{~cm}$ deep. Seedlings were watered three times per week, including once per week with a fertilizer mixture.

Seedlings were randomly divided into treatment and control groups, with the treatment group being exposed to herbivory by $O$. lactea. One snail was added to each pot of the treatment group 5 weeks after the seedlings had germinated. Each treatment pot was fitted with a plastic enclosure with a mesh top to ensure snails remained in their respective pots, while allowing light and air to penetrate. Snails were kept in the treatment pots for 3 days. All seedlings were harvested 2 days after snail removal (6 weeks after germination). The number of replicates varied by species (between 3 and 10) due to germination and survival differences. Seedlings were dried at $60^{\circ} \mathrm{C}$ for $48 \mathrm{~h}$ and the aboveground biomass was weighed.

For each species, seedling biomasses were compared using a two-way ANOVA model with herbivore presence and species as fixed factors in Systat. Post hoc planned comparisons were then made in Systat to assess how the treatment effect varied across species. These post hoc comparisons were made using the Bonferroni method to correct for false discoveries due to the large number of comparisons made. Species for which proportion biomass consumed by $O$. lactea was negative (only $N$. pulchra) were corrected to have a proportion biomass removed of zero. This correction did not affect the outcome of statistical tests. Field and laboratory feeding behaviors were compared using Spearman's rank correlation in Systat.

Experiment III: plant trait analyses

Relative growth rates were determined by growing seedlings of each of the eight grassland species under controlled conditions in the greenhouse. For each species, a single seedling was grown in sand in a conical pot. Seedlings were watered three times per week and fertilized once per week. Seedlings were destructively harvested after 1, 2, 3, 4, 5, and 6 weeks of growth. Above- and below-ground biomass was dried at $60^{\circ} \mathrm{C}$ for $48 \mathrm{~h}$ and weighed. Growth rate was determined by fitting a linear regression through the biomass measures for each species.

To determine plant tissue chemistry, seedlings of each of the eight grassland species (B. carinatus, E. californica, N. pulchra, V. michrostachys, B. diandrus, B. hordeaceus, B. nigra, and C. cardunculus) were grown in the greenhouse in single-species monocultures using growing flats. Six weeks after germination, five leaves were randomly harvested from individuals of each species. The leaf tissue was then dried at $60^{\circ} \mathrm{C}$ for $48 \mathrm{~h}$. Dried leaf material was ground to pass through a 40 mesh screen and $5 \mathrm{mg}$ samples were packed into tin capsules $(n=5$ for all species, except $E$. californica where $n=4$ due to limited germination success). These samples were then analyzed for total carbon and nitrogen content using the combustion gas analyzer method. Relative 
growth rates and $\mathrm{C}: \mathrm{N}$ ratios were compared to both field and laboratory feeding behavior of $O$. lactea using Spearman's rank correlations in Systat.

\section{Results}

Field monocultures of $B$. nigra contained significantly higher densities of $O$. lactea than any other species monoculture tested $\left(F_{7}, 7_{74}=19.931\right.$, $P=0.006)$. While the monocultures of most species supported fairly low densities of snails (from 0 to 1 per $1.5 \mathrm{~m}^{2}$ plot), monocultures of B. nigra supported an average of almost 8 snails per $1.5 \mathrm{~m}^{2}$ plot. There were no significant differences among snail densities in monocultures of the remaining seven species in the field trials. In laboratory feeding trials, there was a significant effect of both species and herbivore preference on seedling biomass, as well as a significant interaction effect $\left(F_{7,74}=11.846, P=0.000\right.$; $F_{1,74}=26.004, P=0.000 ; F_{7,74}=3.011, P=0.008$, respectively). Pairwise comparisons showed that herbivores reduced the size of $B$. nigra $\left(t_{3.6}=6.858\right.$, $P=0.003), \quad C$. cardunculus $\left(t_{7.5}=2.934, \quad P=\right.$ $0.020)$, and $E$. californica $\left(t_{4.8}=2.731, P=0.043\right)$. However, after Bonferroni correction, results were only significant for $B$. nigra. There was no significant effect of $O$. lactea presence on seedling biomass of the other five species.

Field and laboratory feeding behavior of $O$. lactea were not significantly correlated $\left(\rho_{8}=0.419\right.$, $P>0.05$; Fig. 1), however in both settings $B$. nigra was highly preferred over all other species tested. Seedling growth rate was not significantly correlated with field or laboratory feeding behavior of $O$. lactea $\left(\rho_{8}=0.140, \quad P>0.05 ; \quad \rho_{8}=-0.280, \quad P>0.05 ;\right.$ Fig. 2a, b). Additionally, leaf tissue $\mathrm{C}: \mathrm{N}$ was not significantly correlated with field or laboratory feeding behavior of $O$. lactea $\left(\rho_{8}=0.140, P>0.05\right.$; $\rho_{8}=-0.333, P>0.05$, respectively; Fig. 2c, d).

\section{Discussion}

Contrary to our hypothesis, O. lactea did not generally prefer native species over non-native species either in the field or in the laboratory. The species most preferred by $O$. lactea both in the field and in the laboratory was $B$. nigra, a non-native forb

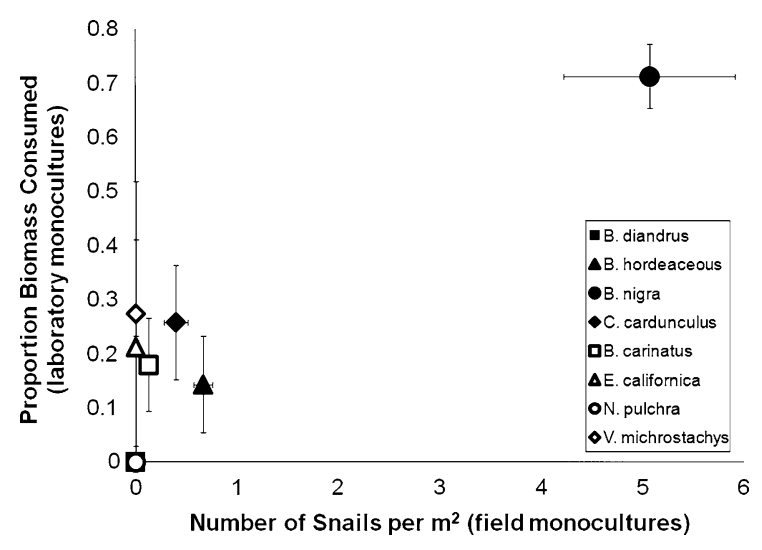

Fig. 1 Behavioral (number of snails per $\mathrm{m}^{2}$ in field monocultures) and feeding (proportion biomass consumed) preferences of $O$. lactea. The proportion biomass consumed is the difference in aboveground biomass between the control plants and the treatment plants divided by the aboveground biomass of the control plants. Species shown as open points are native to southern California grasslands and species shown as solid points are non-native

which co-occurs with $O$. lactea in its native range. This result was unexpected because $B$. nigra is a nonnative species which can be found in high abundance throughout California grasslands, occupying dense stands and in many places growing over six feet tall (Bell and Muller 1973).

Otala lactea's feeding behavior did not correlate strongly with plant growth rate. This result is not consistent with the idea that plants with lower relative growth rates may allocate more to defense than plants with higher relative growth rates (Coley et al. 1985; Grime 1979). Additionally, O. lactea's feeding behavior did not correlate with tissue $\mathrm{C}: \mathrm{N}$, which is not consistent with the general idea that most herbivores are nitrogen limited and would therefore favorably consume plant tissue with higher nitrogen content. However, other chemical or structural cues may be associated with the preference of $O$. lactea for B. nigra. The tissue of Brassicaceae species tends to be high in calcium, iron, potassium, and phosphorus (Kopsell et al. 2000). O. lactea may prefer B. nigra to other grassland species because B. nigra can satisfy $O$. lactea's need for higher levels of these nutrients, possibly used in shell production. Additionally, structural characteristics of B. nigra, such as a tall, non-bending stem, may provide a refuge for $O$. lactea from predators. Many species of snail have been shown to be preyed upon by flatworms (Ohbayashi 
Fig. 2 Effect of species traits on $O$. lactea feeding behavior. Shown is relative growth rate vs. field feeding behavior (a) and laboratory feeding behavior (b) and $\mathrm{C}: \mathrm{N}$ ratio vs. field feeding behavior (c) and laboratory feeding behavior (d) of O. lactea. Species shown as open points are native to southern California grasslands and species shown as solid points are non-native. Standard errors for $\mathrm{C}: \mathrm{N}$ ratio are included, but obscured by the datapoints
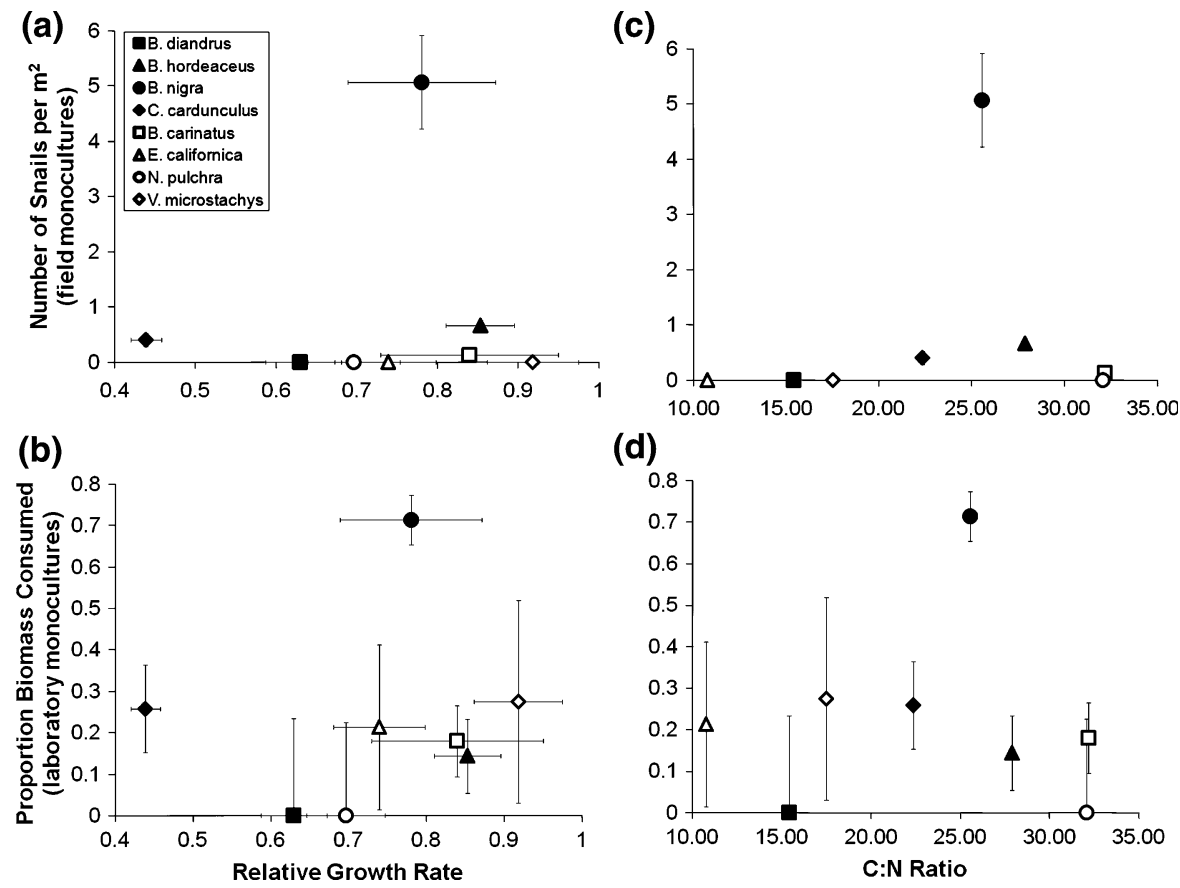

(d)

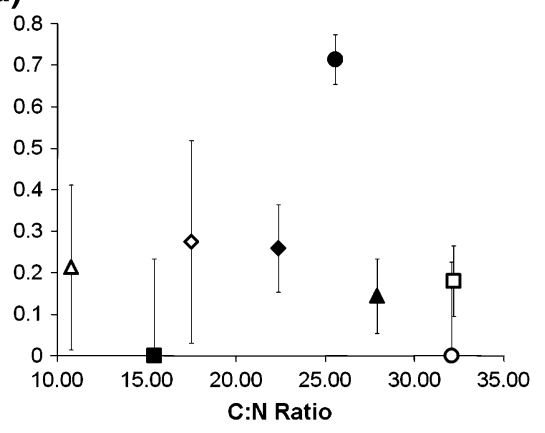

et al. 2005) and rodents (Cowie and Cook 2001). $O$. lactea may associate itself with $B$. nigra in order to spend its dormant period off the ground and away from such ground-dwelling predators.

Although B. nigra appears to be highly targeted by $O$. lactea, it still remains a formidable invader into southern California grasslands. B. nigra may be able to tolerate high levels of feeding by $O$. lactea through its ability to compensate for tissue lost to herbivory (Buschmann et al. 2005; Meyer 2000). If native plant species are not able to compensate for tissue lost to herbivory by $O$. lactea or any other generalist herbivore, then $B$. nigra may be able to maintain a high competitive ability in spite of this herbivory. Additionally, herbivory rates on the native species may be frequency dependent, with rates of herbivory increasing above those observed in this study when native species are relatively rare. For example, Orrock et al. (2008) showed that stands of B. nigra supported high levels of small, native mammals which drastically reduced the establishment of the native bunchgrass Nassella pulchra. Similarly, by supporting high levels of $O$. lactea, B. nigra's competitive ability against other native species may be enhanced. Additional research directed toward how herbivory by $O$. lactea affects $B$. nigra's ability to compete with native species in the field would be worthwhile.
The invasional meltdown and enemy inversion hypotheses suggest that non-native herbivores may indirectly facilitate the invasion of non-native plant species by preferentially targeting native plant species or otherwise altering the environment to favor the nonnative plant (Colautti et al. 2004; Parker et al. 2006; Simberloff and Von Holle 1999). The results of the current experiments do not support these hypotheses. Rather we show that a non-native herbivore, O. lactea, does not preferentially target native plant species. Additionally, we show that intense herbivory on a nonnative plant species can occur when a non-native herbivore is able to accompany the plant to its new range. In our study, the presence of the non-native herbivore does not appear to enhance the success of the non-native plant species in its new range. Thus, our study provides evidence that an herbivore species which follows a co-occurring plant species into its invasive range can have a strong negative effect on the performance of that plant species. We term this $(+/-)$ interaction "invasional antagonism."

While the $(+/-)$ interaction between the plant and herbivore in invasional antagonism parallels the interaction between a biocontrol agent and its target, the case of invasional antagonism is distinct from that of biocontrol in an important way. Biocontrol agents are intentionally introduced to a system to control an 
invasive plant species, while in the case of invasional antagonism the herbivore species is accidentally introduced. This distinction has important consequences for the outcome of the herbivore's introduction. Because of the care that goes into the intentional introduction of a biocontrol agent, it should presumably not affect the native community in a negative way. However, in the case of invasional antagonism, the exotic herbivore may have a negative effect on the native community in addition to its strong negative effect on the invasive plant species. These interactions may eventually lead the exotic herbivore itself to become invasive in the case of invasional antagonism.

Antagonistic interactions between accidentally introduced plants and herbivores are likely common and may increase in frequency as both accidental and intentional species introductions continue in the future. However, these antagonistic relationships between non-native plants and herbivores are seldom reported in the scientific literature (but see Egan and Irwin 2008; Strauss et al. 2009). Nonetheless, we believe that these interactions may be important in determining the success of an invasive plant species in its invasive range. By focusing our attention on identifying additional cases of invasional antagonism, we may be able to exploit these negative plantherbivore interactions for use as effective biocontrol agents in the future.

Acknowledgments We are grateful to The Nature Conservancy and T. Smith for permission to work in the Irvine Ranch Land Reserve and the entire Suding Lab for their invaluable assistance in designing and setting up the experiments, analyzing the data, and discussing the results. We also thank D. Simberloff and an anonymous reviewer for comments which greatly improved this manuscript. The University of California, Irvine Undergraduate Research Opportunities Program (UROP) and Summer Undergraduate Research Program (SURP) funded this work.

Open Access This article is distributed under the terms of the Creative Commons Attribution Noncommercial License which permits any noncommercial use, distribution, and reproduction in any medium, provided the original author(s) and source are credited.

\section{References}

Bell DT, Muller CH (1973) Dominance of California annual grasslands by Brassica nigra. Am Midl Nat 90:277-299
Buschmann H, Edwards PJ, Dietz H (2005) Variation in growth pattern and response to slug damage among native and invasive provenances of four perennial Brassicaceae species. J Ecol 93:322-334

Catford JA, Jansson R, Nilsson C (2009) Reducing redundancy in invasion ecology by integrating hypotheses into a single theoretical framework. Divers Distrib 15:22-40

Colautti RI, Ricciardi A, Grigorovich IA, MacIsaac HJ (2004) Is invasion success explained by the enemy release hypothesis? Ecol Lett 7:721-733

Coley PD, Bryant JP, Chapin FS III (1985) Resource availability and plant antiherbivore defense. Science 230:895-899

Cowie RH (2001) Can snails ever be effective and safe biocontrol agents? Int J Pest Manag 47:23-40

Cowie RH, Cook RP (2001) Extinction or survival: partulid tree snails in American Samoa. Biodivers Conserv 10:143-159

Crooks JA (2002) Characterizing ecosystem-level consequences of biological invasions: the role of ecosystem engineers. Oikos 97:153-166

Egan JF, Irwin RE (2008) Evaluation of the field impact of an adventitious herbivore on an invasive plant, yellow toadflax, in Colorado, USA. Plant Ecol 199:99-114

Elliott AC, Pierce BA (1992) Size, growth-rate, and multiplelocus heterozygosity in the land snail (Otala lactea). J Hered 83:270-274

Grime J (1979) Plant strategies and vegetative processes. Wiley, New York

Harpole WS, Suding KN (2007) Frequency-dependence stabilizes competitive interactions among four annual plants. Ecol Lett 10:1164-1169

Hoffmeister TS, Vet LEM, Biere A, Holsinger K, Filser J (2005) Ecological and evolutionary consequences of biological invasion and habitat fragmentation. Ecosystems 8:657-667

Keane RM, Crawley MJ (2002) Exotic plant invasions and the enemy release hypothesis. Trends Ecol Evol 17:164-170

Kopsell DA, Randle WM, Mills HA (2000) Nutrient accumulation in leaf tissue of rapid-cycling Brassuca oleracea responds to increasing sodium selenate concentrations. J Plant Nutr 23:927-935

Levine JM, Vila M, D’Antonio CM, Dukes JS, Grigulis K, Lavorel S (2003) Mechanisms underlying the impacts of exotic plant invasions. Proc R Soc Lond B Biol Sci 270:775-781

Levine JM, Adler PB, Yelenik SG (2004) A meta-analysis of biotic resistance to exotic plant invasions. Ecol Lett 7:975-989

Meyer GA (2000) Interactive effects of soil fertility and herbivory on Brassica nigra. Oikos 88:433-441

Ohbayashi T, Okochi I, Sato H, Ono T (2005) Food habit of Platydemus manokwari De Beauchamp, 1962 (Tricladida: Terricola: Rhynchodemidae), known as a predatory flatworm of land snails in the Ogasawara (Bonin) Islands, Japan. Appl Entomol Zool 40:609-614

Orrock JL, Witter MS, Reichman OJ (2008) Apparent competition with an exotic plant reduces native plant establishment. Ecology 89:1168-1174

Parker J, Burkepile D, Hay M (2006) Opposing effects of native and exotic herbivores on plant invasions. Science 311:1459-1461 
Pearson DE, McKelvey KS, Ruggiero LF (2000) Non-target effects of an introduced biological control agent on deer mouse ecology. Oecologia 122:121-128

Sabath MD, Boughton WC, Easteal S (1981) Expansion of the range of the introduced toad Bufo marinus in Australia from 1935 to 1974 . Copeia 1981:676-680

Shea K, Chesson P (2002) Community ecology theory as a framework for biological invasions. Trends Ecol Evol 17:170-176

Simberloff D, Von Holle B (1999) Positive interactions of nonindigenous species: invasional meltdown? Biol Invasions 1:21-32
Strauss SY, Stanton ML, Emery NC, Bradley CA, Carleton A, Dittrich-Reed DR, Ervin OA, Gray LN, Hamilton AM, Rogge JH, Harper SD, Law KC, Pham VQ, Putnam ME, Roth TM, Theil JH, Wells LM, Yoshizuka EM (2009) Cryptic seedling herbivory by nocturnal introduced generalists impacts survival, performance of native and exotic plants. Ecology 90:419-429 